\title{
The Cpc1 Regulator of the Cross-Pathway Control of Amino Acid Biosynthesis Is Required for Pathogenicity of the Vascular Pathogen Verticillium Iongisporum
}

\author{
Christian Timpner, Susanna A. Braus-Stromeyer, Van Tuan Tran, and Gerhard H. Braus \\ Institut für Mikrobiologie und Genetik, Abteilung Molekulare Mikrobiologie und Genetik Georg-August-Universität, 37077 \\ Göttingen, Germany
}

Submitted 16 March 2013. Accepted 18 July 2013.

\begin{abstract}
The plant-pathogenic fungus Verticillium longisporum is a causal agent of early senescence and ripening in cruciferous crops like Brassica napus. Verticillium wilts have become serious agricultural threats in recent decades. Verticillium species infect host plants through the roots and colonize xylem vessels of the host plant. The xylem fluid provides an environment with limited carbon sources and unbalanced amino acid supply, which requires $V$. longisporum to induce the cross-pathway control of amino acid biosynthesis. RNAmediated gene silencing reduced the expression of the two CPC1 isogenes (VICPC1-1 and VICPC1-2) of the allodiploid $V$. longisporum up to $85 \%$. VICPC1 encodes the conserved transcription factor of the cross-pathway control. The silenced mutants were highly sensitive to amino-acid starvation, and the infected plants showed significantly fewer symptoms such as stunting or early senescence in oilseed rape plant infection assays. Consistently, deletion of single $C P C 1$ of the haploid $V$. dahliae resulted in strains that are sensitive to amino-acid starvation and cause strongly reduced symptoms in the plant-host tomato (Solanum lycopersicum). The allodiploid $V$. longisporum and the haploid $V$. dahliae are the first phytopathogenic fungi that were shown to require $C P C 1$ for infection and colonization of their respective host plants, oilseed rape and tomato.
\end{abstract}

With an increasing demand for biofuel, plants like maize, oilseed rape, or oil palm become more important to counteract the limitation of crude oil. In Europe, cultivation of oilseed rape has increased during the last decade. An important problem is the susceptibility toward pathogens such as Verticillium longisporum, a soil-borne vascular pathogen of oilseed rape Brassica napus (Karapapa et al. 1997; Zeise and von Tiedemann 2002a). Since the 1960s, wilts have become a major threat to oilseed crops in northern Europe, including Sweden, Germany, Poland, and also France (Karapapa et al. 1997; Zeise and von Tiedemann 2001, 2002a and b). In Germany, V. longisporum infection on rapeseed has significantly increased since the 1980s (Daebeler et al. 1988; Günzelmann and Paul 1990; Zeise and Seidel 1990).

Corresponding author: G. H. Braus; Telephone: +49 55139 33771; Fax: +49 5513938 20; E-mail: gbraus@gwdg.de

* The $\boldsymbol{e}$-Xtra logo stands for "electronic extra" and indicates that eight supplementary figures are published online and that Figures 3 and 4 appear in color online.

(C) 2013 The American Phytopathological Society
V. longisporum infects its host through the root, colonizes the oilseed rape plant, and produces microsclerotia in the necrotrophic stage (Eynck et al. 2007; Zhou et al. 2006). Microsclerotia rest in the soil and can live for several years in this dormant form (Heale and Karapapa 1999; Schnathorst 1981). $V$. longisporum directly penetrate the epidermal cells in the root-hair zone for infection (Eynck et al. 2007). The fungus grows inter- and intracellularly in the root cortex toward the central cylinder and colonizes the xylem vessels. Whereas several xylem vessels are filled with mycelium and conidia, most of the nearby vessels remain without infection. With progression of ripeness and senescence of the diseased plants the fungus starts to generate microsclerotia. The resting structures are released into the soil with the residues of plant material after harvesting and can again infect healthy plants. For most parts of its life in the host plant, $V$. longisporum is restricted in the vascular system of the oilseed rape Brassica napus (Eynck et al. 2007).

The xylem is responsible for the transport of water and soluble mineral nutrients from the roots throughout the plant. Xylem sap, which has been analyzed in several studies (Floerl et al. 2012; Iven et al. 2012; Ratzinger et al. 2009; Singh et al. 2010, 2012), is not rich in nutrients and can contain a number of organic acids (Lopez-Millan et al. 2000). They include low amounts of amino acids (Singh et al. 2010). Glutamic acid, aspartic acid, and serine are the most abundant amino acids in leaf mesophyll cells of $B$. napus, in which the concentration of the aromatic amino acids ranges from 1.2 to $2.1 \%$ of the total amino acids under low nitrogen supply conditions (Singh et al. 2010; Tilsner et al. 2005).

Fungi, which are usually prototrophic, prefer to acquire amino acids from their environment by their uptake systems. External amino-acid supply reduces the cellular biosynthesis by multiple enzyme feedback mechanisms. The basal expression of genes for amino-acid biosynthesis is sufficient to provide enough amino acids for cellular translation in a minimal medium, but an imbalanced amino-acid diet requires increased transcription of amino-acid biosynthetic genes. This is provided by a transcriptional network, which is called cross-pathway control for filamentous fungi or general control of amino acids in yeast (Carsiotis and Jones 1974; Carsiotis et al. 1974; Hinnebusch 1986). Numerous genes are activated (Hinnebusch and Natarajan 2002; Kleinschmidt et al. 2005; Natarajan et al. 2001) by a central conserved c-jun-like transcriptional activator, which is Gcn4 (general control non-derepressed) in Saccharomyces cerevisiae (Hinnebusch 1984; Mösch et al. 1991) and which is conserved to ATF4 in humans (Kilberg et al. 2009; Shan et al. 2009). In filamentous fungi, CpcA (cross- 
pathway control) is the counterpart in Aspergillus spp. (Eckert et al. 2000; Hoffmann et al. 2001; Krappmann et al. 2004; Wanke et al. 1997) or Cpc1 in Neurospora crassa (Paluh et al. 1988).

Protein levels of the yeast Gcn4 activator are low when amino acids are abundant and are increased by enhanced translation and increased protein stability during amino-acid starvation (Albrecht et al. 1998). Filamentous fungi possess an additional transcriptional autoactivation that is not present in yeast. Aspergillus nidulans CpcA binds to CPRE (cross-pathway control recognition elements) that locate not only within the promoter region of target genes but also within its own $C p c A$ promoter, resulting in increased transcript levels for the activator (Hoffmann et al. 2001).

A requirement of $\mathrm{CpcA}$ for pathogenicity of the human opportunistic pathogen A. fumigatus had been demonstrated (Krappmann et al. 2004) but the role of CpcA homologs in plant-pathogenic fungi is unclear. Transcript levels of the CpcA homolog CPCl gene of the plant-pathogen $V$. longis porum increased when cultivated in the presence of plant xylem sap and suggested an imbalanced amino-acid supply (Singh et al. 2010). In this study, we examined whether the $C P C 1$ genes of the Verticillium cross-pathway control activator play a role in plant pathogenicity.

\section{RESULTS}

V. longisporum carries two $C P C 1$ regulatory isogenes.

Sequencing of the cDNA library of $V$. longisporum V143 revealed the presence of two transcripts for the cross-pathway transcriptional regulator $\mathrm{V} 1 \mathrm{Cpc} 1$. The corresponding isogenes that had originally been named $C P C A$ (Singh et al. 2010) were renamed (VlCPC1-1 and VlCPC1-2) to refer to the nomenclature of related Verticillium species. Both $C P C 1$ chromosomal loci of $V$. longisporum were compared with the corresponding genes of haploid $V$. dahliae or $V$. albo-atrum (Fig. 1). Primer pair CPC1Seq-L/CPC1Seq-R (Table 1) was designed according to the CPC1 locus (VDAG_10113) from the Broad Institute (Cambridge, MA, U.S.A.) $V$. dahliae genome assembly (Klosterman et al. 2011). Sequencing of the resulting PCR products from $V$. dahliae and $V$. albo-atrum revealed unique single sequences of $725 \mathrm{bp}$ for $\mathrm{VdCPCl}$ or $723 \mathrm{bp}$ for $\mathrm{VaCPCl}$. In contrast, cloning and sequencing of the polymerase chain reaction (PCR) products from $V$. longisporum revealed two distinct sequences for $V l C P C 1$, corresponding to isogenes $V l C P C 1-1$ and VlCPC1-2, with lengths of 725 or 723 bp similar to $V d C P C 1$ and $V a C P C 1$, respectively (Supplementary Fig. S1). In total, there are more than 60 different nucleotides between all four sequences. The deduced open reading frames (ORF) of all four genes consist of two exons, each, of a length of 13 or 653 base pairs (bp), separated by single introns that correspond to two related groups. The introns of $\mathrm{VdCPCl}$ and $V l C P C 1-1$ have a length of $59 \mathrm{bp}$, whereas $V a C P C 1$ and the second isogene $V l C P C 1-2$ share a length of $57 \mathrm{bp}$.

In contrast to the yeast GCN4 gene, which is not significantly autoregulated (Albrecht et al. 1998), all Verticillium $C P C 1$ genes carry one TGACTCA CPRE in their own promoter 985 bp upstream of the ORF (Fig. 1A). Conserved CPRE consist of a palindromic sequence element constituted by a central CG pair that is flanked by TGA halfsites (Oliphant et al. 1989).
A

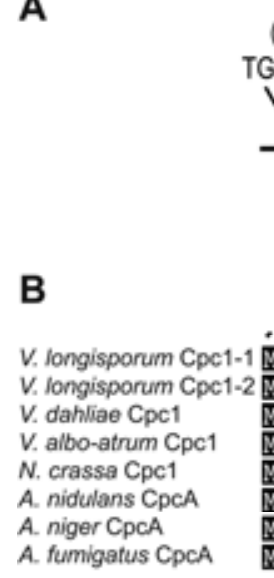

(n)

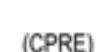

(CPRE)

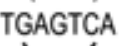

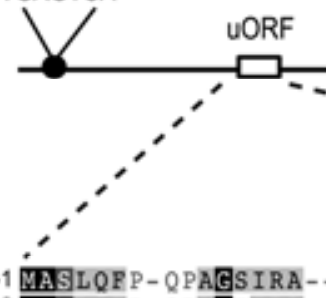

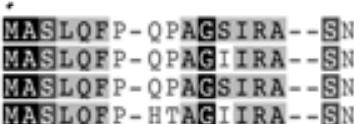

MASLOPP - HTAGTIRA-

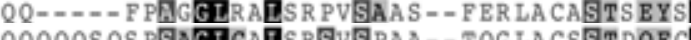

MASFTLA HAA FGSESEPRSQQQQEQQQ---FSARGLRADPCSVGPASRTTRGRI CSSI P-- YG

E1

\section{E2} CPC1 bZIP
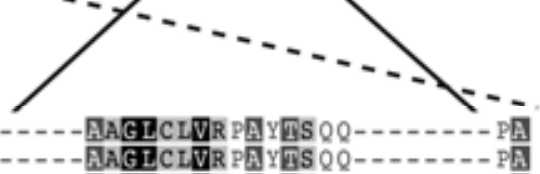

\section{C}
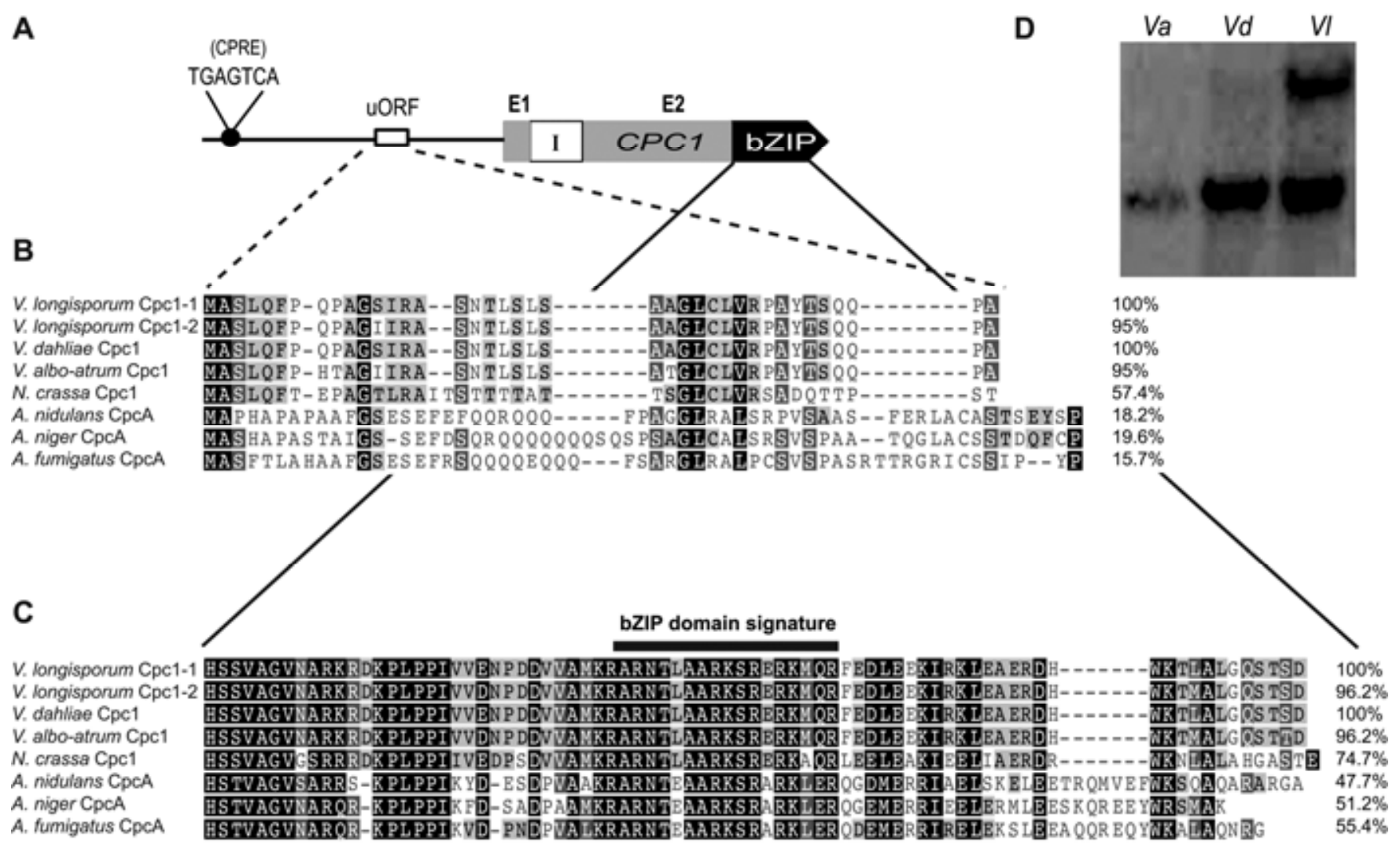

$100 \%$

$95 \%$

$100 \%$

$95 \%$

$57.4 \%$

$18.2 \%$

$19.6 \%$ $15.7 \%$

Fig. 1. The CPC1 loci of Verticillium species. A, The black dot indicates the putative cross-pathway control recognition element (CPRE) with the sequence $5^{\prime}$-TGAGTCA-3'. The conserved leucine zipper (bZIP) region at the C-terminus of $C P C 1$ is in black. The upstream open reading frame (uORF) in the $5^{\prime}$ leader region is represented by a white box. B, uORF alignments of the deduced amino-acid sequences in comparison to corresponding uORF of CPCA/CPC1 genes of Aspergillus fumigatus, A. nidulans, A. niger, or Neurospora crassa. White letters in black boxes represent conserved and gray boxes partially conserved amino-acid residues. C, Alignments of the C-terminal leucine zipper regions of the same genes as in B. The bZIP transcription factors basic domain signature (InterProScan PS00036) is indicated by a black line. D, Southern hybridization analysis of the single copy $V$. albo-atrum or $V$. dahliae CPC1 genes in comparison to two isogenes in V. longisporum. Genomic DNA was digested with BamHI with a 456-bp VlCPC1 sequence as probe. 
CPRE were also found in various promoters of CPCl homologs and suggest binding by the activator and transcriptional autoregulation (Hoffmann et al. 2001; Krappmann et al. 2004; Tian et al. 2007). The earlier finding that $V l C P C 1$ mRNAs are induced during infection of B. napus or Arabidopsis thaliana (Singh et al. 2010) might be due to an induced cross-pathway control.

A small upstream ORF (uORF), located at -424 to $-304 \mathrm{bp}$ upstream of the translational start codon, is almost identical in all Verticillium CPC1 genes (Fig. 1B). uORF are part of the translational control of fungal $C P C 1$ genes and the deduced primary sequence of 39 amino acids of the Verticillium uORF shows $57 \%$ identities to the corresponding uORF of $N$. crassa CPC1 (Paluh et al. 1988) This suggests that, in addition to the transcriptional autoregulation, Verticillium CPC1 transcripts are also regulated at the level of translation.

The C-terminal basic leucine zipper region mediates dimerization and DNA binding (Struhl et al. 1988) and is highly conserved in filamentous fungi. The sequences of $\mathrm{VlCPCl}-1$ and VdCPCl are $100 \%$ identical, whereas VlCPCl-2 and VaCPCl are $97 \%$ similar to this sequence and differ in two amino acids. The corresponding genes of $N$. crassa and various Aspergillus spp. vary between 74 and $47 \%$ identical amino acid residues, respectively (Fig. 1C). An overall comparison of the four $\mathrm{CPCl}$ genes from $V$. longisporum, $V$. dahliae, and $V$. albo-atrum shows specific small nucleotide variations that are shared between $V d C P C l$ and the isogene $V l C P C 1-1$ and are distinct to the gene pair V. albo-atrum VaCPCl and the other isogene VlCPC1-2. Southern hybridization confirmed the presence of two $C P C 1$ isogenes in $V$. longisporum, in contrast to single genes in $V$. dahliae or V. albo-atrum (Fig. 1D). This and a phylogenetic analysis (Fig. 2) further support that the V. longisporum genome is the result of a hybridization event between two distinct but related parental Verticillium species (Inderbitzin et al. 2011; Tran et al. 2013). All Verticillium CPC1 genes group together with other pathogenic fungi such as Colletotrichium or
Fusarium spp. and separate them from saprophytes such as Aspergillus spp. or single-cell yeast $S$. cerevisiae (Fig. 2).

\section{VICPC1-silenced mutants grow like wild type on a minimal medium but are strongly reduced in growth under amino acid starvation conditions.}

The presence of two $C P C l$ isogenes of $V$. longisporum required RNA silencing (Nakayashiki 2005) to examine the role of the cross-pathway control regulatory gene for the fungal life cycle. A hairpin double-stranded RNA approach combined with the hygromycin B marker selection was applied for RNA silencing of VlCPC1-1 and VlCPC1-2. The copy number of integrated hairpin constructs was determined by Southern hybridization (Supplementary Fig. S2A). The tested transformants showed one to two copies of the silencing construct in the genome. The extent of silencing was determined for hygromycin B-resistant transformants by reverse transcription (RT)PCR by the ratio of the amplification of VlCPCl between the respective transformants and the unsilenced wild type and varied considerably among different transformants. Transformants with a reduced activity of less than $20 \%$ were further analyzed (Fig. 3). One day after inoculation on minimal medium (Czapek Dox agar [CDA]), the silenced $V$. longisporum strain could grow like the wild type, and both strains showed increased mycelial growth and first conidia after 2 days of cultivation (data not shown). Radial growth of both strains was similar for 15 days (Fig. 3; Supplementary Fig. S3). Therefore, growth under minimal-nutrition conditions without any amino-acid supply is like wild type when $C P C 1$ transcription is reduced to less than $20 \%$ at the RNA level in the silenced mutants.

In contrast, cultivation on minimal medium supplemented with the amino-acid analog 5-methyl-tryptophan (5-MT), which acts as false feedback inhibitor and causes tryptophan starvation (Schürch et al. 1974), resulted in a significant reduction in the growth rate. After 2 days, wild type showed a mycelial net with few conidia, whereas the $C P C 1$-silenced Verticil-

Table 1. Primers used in this study

\begin{tabular}{|c|c|c|}
\hline Primer & Sequence $\left(5^{\prime}-3^{\prime}\right)$ & Reference \\
\hline OLG70 & CAGCGAAACGCGATATGTAG (20) & \\
\hline OLG71 & GGCTTGTAGGGGGTTTAGA (19) & Eynck et al. 2007 \\
\hline H2A-RT1 & CCCGTGACAACAAGAAGACTCG (22) & \\
\hline$H 2 A-\mathrm{RT} 2$ & GCAGGAAAGAAAAGCCAAAACC (22) & This study \\
\hline CPC1RT1 & CCCATCGTTGTTGAGAATCCAG (22) & \\
\hline CPC1RT2 & GACTGACCCAAAGCCAAGGTCT (22) & This study \\
\hline Probe $C P C 1-\mathrm{L}$ & CGGCCCTCAAAAATTGTTCC (20) & \\
\hline Probe $C P C 1-\mathrm{R}$ & GACTTAAATTGAGATATCCG (20) & This study \\
\hline$C P C 1 \mathrm{Seq}-\mathrm{L}$ & ATGGCTTCCCTCCAGTTCC (19) & \\
\hline$C P C 1 \mathrm{Seq}-\mathrm{R}$ & CTAGTCGCTGGTTGACTGACC (21) & This study \\
\hline$V d C P C 1 \mathrm{KOF} 1-\mathrm{L}(P a c \mathrm{I})$ & GGGTTAATTGGCTATCGAGCATACGAAGAAC (31) & \\
\hline$V d C P C 1 \mathrm{KOF} 1-\mathrm{R}(\operatorname{Sac} \mathrm{I})$ & GGGGAGCTCCCATCCATATATTCTGGCGATT (31) & This study \\
\hline$V d C P C 1 \mathrm{KOF} 2-\mathrm{L}(X b a \mathrm{I})$ & GGGTCTAGAGAGGTTTCCTACATTCTGACTTT (32) & \\
\hline VdCPC1KOF2-R (HindIII) & GGGAAGCTTACACTAAGGAATAAGGCCTAAGATT (34) & This study \\
\hline$V d C P C 1 \mathrm{PCR}-\mathrm{L}(\mathrm{P} 1)$ & ATGGCTTCCCTCCAGTTCC (19) & \\
\hline$V d C P C 1 \mathrm{PCR}-\mathrm{R}(\mathrm{P} 2)$ & GTATTAAAACTTGTGCCTCG (20) & This study \\
\hline$V d C P C 1$ KOProbe-L & TCCCAACAACCTGCCTAAAC (20) & \\
\hline$V d C P C 1 \mathrm{KOProbe}-\mathrm{R}$ & AGAGTCCAGAACAGCACGGT (20) & This study \\
\hline$V l C P C 1$ gate-L & GGGGACAAGTTTGTACAAAAAAGCAGGCTTCATGAACATCGCGGATTTCG (50) & \\
\hline VlCPC1gate-R & GGGGACCACTTTGTACAAGAAAGCTGGGTCCTGCCAGAGTGTTGCGAGC (49) & This study \\
\hline $\operatorname{Arg} 6 \mathrm{RT} 1 \mathrm{~L}$ & TTTATTGCTCGGCTTGTGGTTC (22) & \\
\hline Arg6RT1R & CTTCTGCCCTTCGCTTCTCTTC (22) & This study \\
\hline Leu4RT1L & ATGCTCAAGGACCCCATCAAGA (22) & \\
\hline Leu4RT1R & GCCACTTCTCATCGCCACTCAT (22) & This study \\
\hline Lys1RT1L & CCGAGATTGTTGAGAGCGACAT (22) & \\
\hline Lys1RT1R & GGTGTAGATGGGGACAGGGTTG (22) & This study \\
\hline Trp5RT1L & TGAGTTACGGCGAGGAGAGG (20) & \\
\hline Trp5RT1R & GCGATAAGGGGAACATAGGAGAG (23) & This study \\
\hline
\end{tabular}


lium longisporum strain ( $V l C P C 1 \mathrm{sm})$ formed short hyphae without conidia (data not shown). Radial growth of the silenced mutant was significantly retarded during 5-MT induced starvation in comparison with the wild type, when the colony diameter was determined after 15 days. Real-time PCR revealed that the wild type shows a significant increase in $C P C l$ transcription during starvation, whereas the silenced mutant is unable to achieve even basal wild-type $C P C 1$ levels of nonstarvation conditions (Fig. 3). Methionine starvation induced by $2 \mathrm{mM}$ methionine sulfoximine, which inhibits glutamine synthetase required for the biosynthesis of glutamine, confirmed these results and also resulted in a specific growth reduction of the silenced strain.

The single $C P C 1$ gene of $V$. dahliae was deleted as a control to evaluate the impact of the residual activity of less than $20 \%$ in the silenced $V$. longisporum mutant under nonstarvation and starvation condition. The $V$. dahliae deletion mutant ( $V d \triangle C P C l)$ was able to grow on minimal medium with a similar colony morphology as wild type (Fig. 3). Growth of the mutant is not affected when the carbon sources were exchanged for cultivation by standard carbon sources like sucrose, glucose, or fructose, but there is a slight growth reduction when plant-derived carbon sources like mannose, lignin, cellulose, or xylan were provided for growth (Fig. 4). In contrast, adding 5-MT to the medium inhibited growth of $V d \triangle C P C l$ mutant completely, and even germinating spores during the initial phase could not be monitored. Real-time PCR showed that $C P C 1$ transcription is absent in the $V d \triangle C P C l$ deletion strain, whereas the wild type similar to $V$. longisporum increases transcription significantly during starvation (Fig. 3C).

Previous studies in the plant pathogen Fusarium fujikuroi revealed the cross-pathway controlled expression of specific

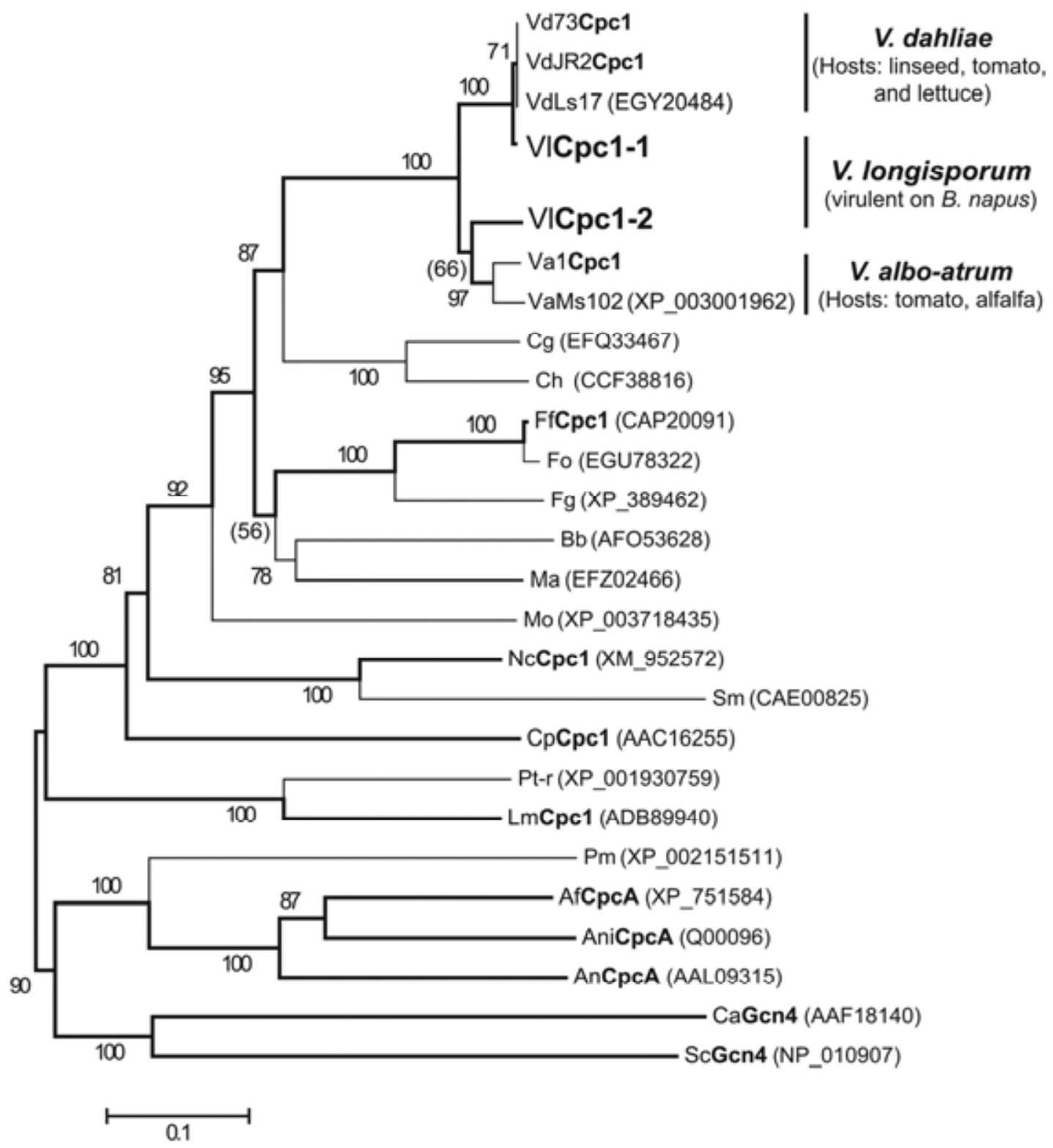

Fig. 2. Phylogenetic analysis for deduced Cpc1 proteins of three Verticillium species in comparison with the orthologs of other filamentous fungi. The virulent hybrid pathogen Verticillium longisporum possesses two isogenes encoding deduced Cpc1-1 or Cpc1-2, which are similar to V. dahliae and V. albo-atrum, respectively. Other Cpc1-like proteins were deduced from the encoding genes with the provided accession numbers (in brackets), which were extracted from GenBank. Thick black lines indicate that the corresponding genes have been verified as cross-pathway regulatory genes. Two bootstrap values smaller than 70 are indicated in brackets. $V l=V$. longisporum, $V d=V$. dahliae, Va $=V$. albo-atrum, $C g=$ Colletotrichum graminicola,$C h=C$. higginsianum, $F f=$ Fusarium fujikuroi, Fo $=F$. oxysporum, Fg $=$ F. graminearum, $P t-r=$ Pyrenophora tritici-repentis, Lm $=$ Leptosphaeria maculans, Bb $=$ Beauveria bassiana, $M a=$ Metarhizium anisopliae, $M o=$ Magnaporthe oryzae, $N c=$ Neurospora crassa, Sm $=$ Sordaria macrospora $, C p=C r y p h o n e c t r i a ~ p a r a s i t i c a, P m=P e n i-$ cillium marneffei, $A f=$ Aspergillus fumigatus, Ani $=A$. niger, $A n=A$. nidulans, $C a=$ Candida albicans, and $S c=$ Saccharomyces cerevisiae . 
genes involved in amino-acid biosynthesis (Schönig et al. 2009). We investigated whether $C P C 1$ of Verticillium activates the corresponding genes, including LYS1 for lysine, LEU4 for leucine, ARG6 for arginine, and TRP5 for tryptophan biosynthesis (Supplementary Fig. S4). Expression of all four genes is regulated by $C P C 1$. Whereas wild type or the complementation strain showed significant increases of target-gene expres- sion during starvation, there was no detectable expression of these genes in the $\triangle C P C 1$ deletion strain. Fungal spore formation was similar for the $\triangle C P C 1$ mutant and the wild-type strain, resulting in comparable amounts of spores and the same capability of the spores to germinate, based on the number of germinated spores 4,6 , and $8 \mathrm{~h}$ after inoculation (Supplementary Fig. S5).
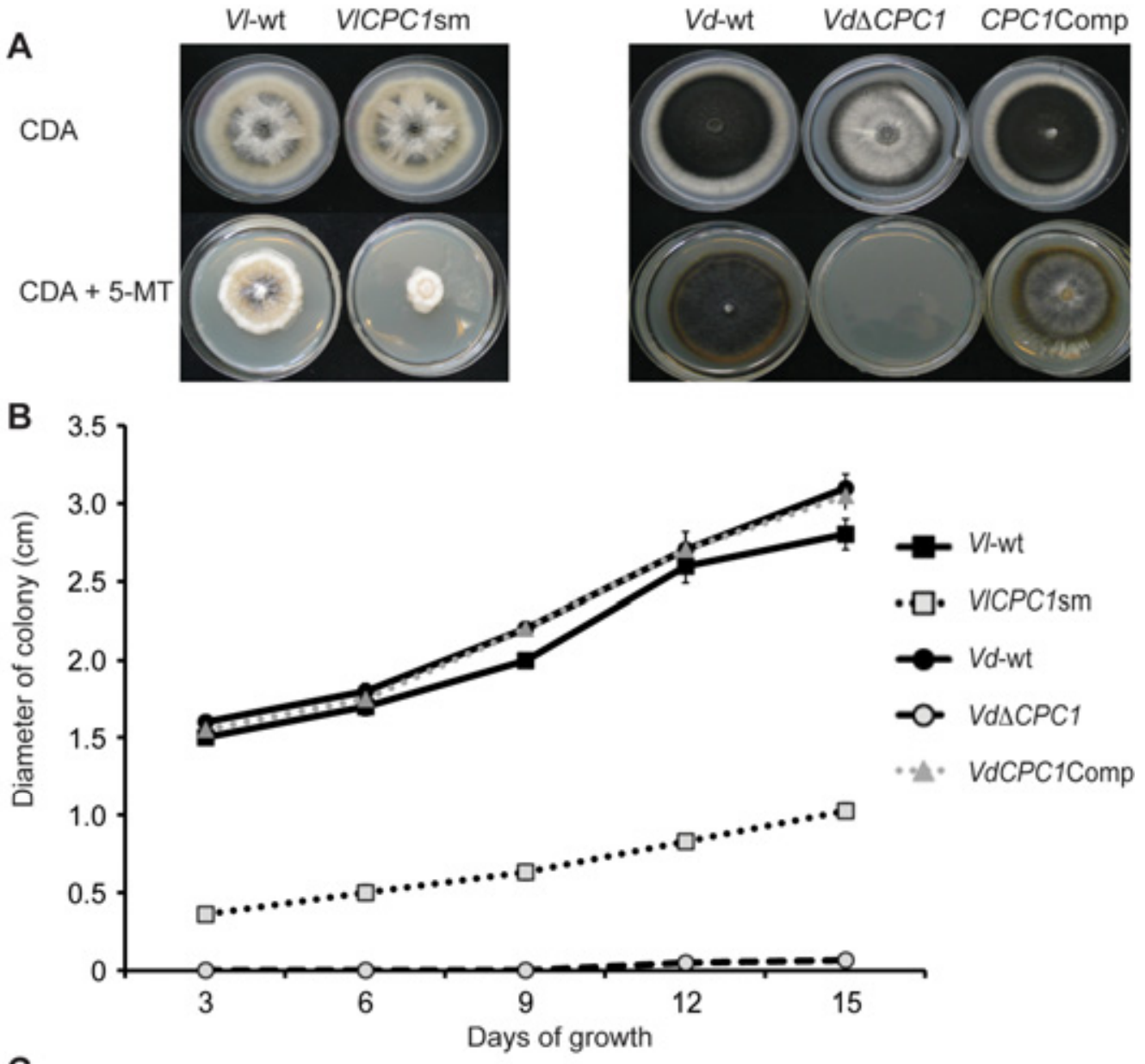

C
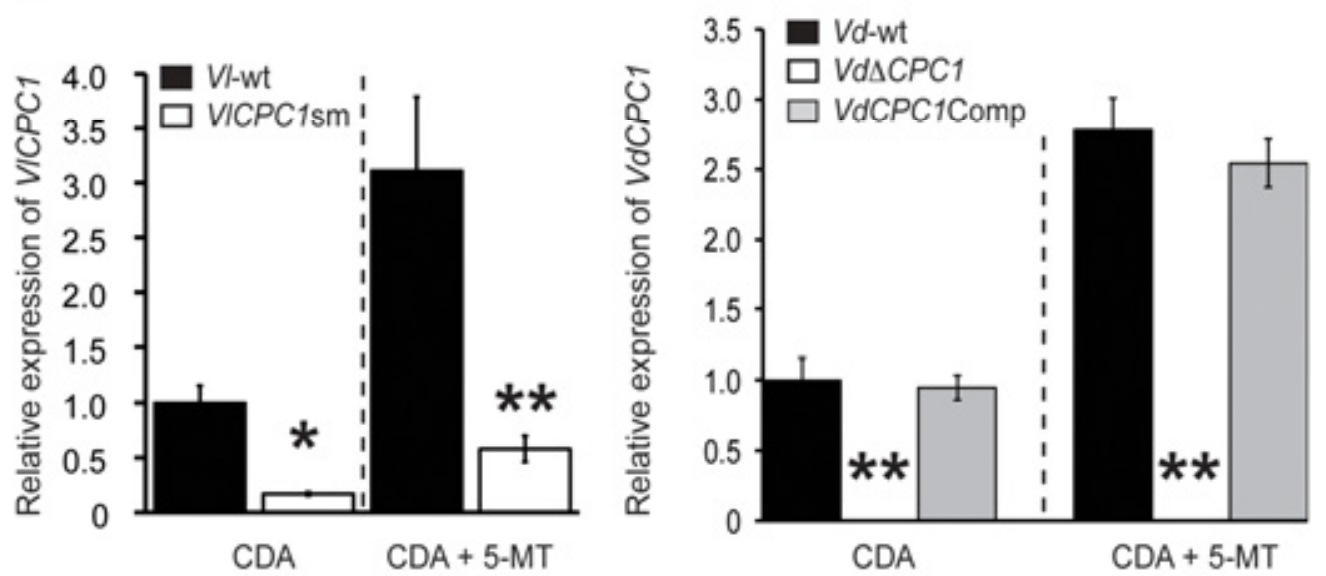

Fig. 3. Influence of 5-methyl-tryptophan (5-MT) on Verticillium longisporum and V. dahliae growth. A, Colonies of V. longisporum, VlCPC1-silenced mutants, $V$. dahliae, and $V$. dahliae knockout mutant in the presence or absence of amino-acid limitation. Colonies were grown on minimal medium (CDA) after 9 days of inoculation. Amino-acid starvation was induced by supplementation with $5 \mathrm{mM} \mathrm{5-MT.} \mathrm{B,} \mathrm{The} \mathrm{V.} \mathrm{longisporum} \mathrm{wild} \mathrm{type} \mathrm{(Vl-wt)} \mathrm{and} \mathrm{the}$ silenced mutant $(V l C P C 1 \mathrm{sm})$, as well as $V$. dahliae wild type ( $V d$-wt), and $V$. dahliae knockout mutant ( $V d \Delta C P C 1)$ were plated on CDA containing 5 mM 5-MT. Diameters of colonies were measured at indicated days after inoculation. Error bars represent standard deviation $(n=5)$. C, Relative expression of $V l C P C 1$ and $V d C P C 1$ transcripts in the $V$. longisporum wild type and the silenced mutant VlCPClsm as well as $V$. dahliae wild type and the deletion mutant $V d \triangle C P C 1$, respectively, under inducing and noninducing conditions measured by quantitative real-timepolymerase chain reaction. The target cDNAs were normalized to the transcripts of the housekeeping gene $H 2 A$ histone. Significant differences between the wild type and mutants are illustrated by asterisks (** and * indicate $P \leq 0.01$ and 0.05 , respectively). 

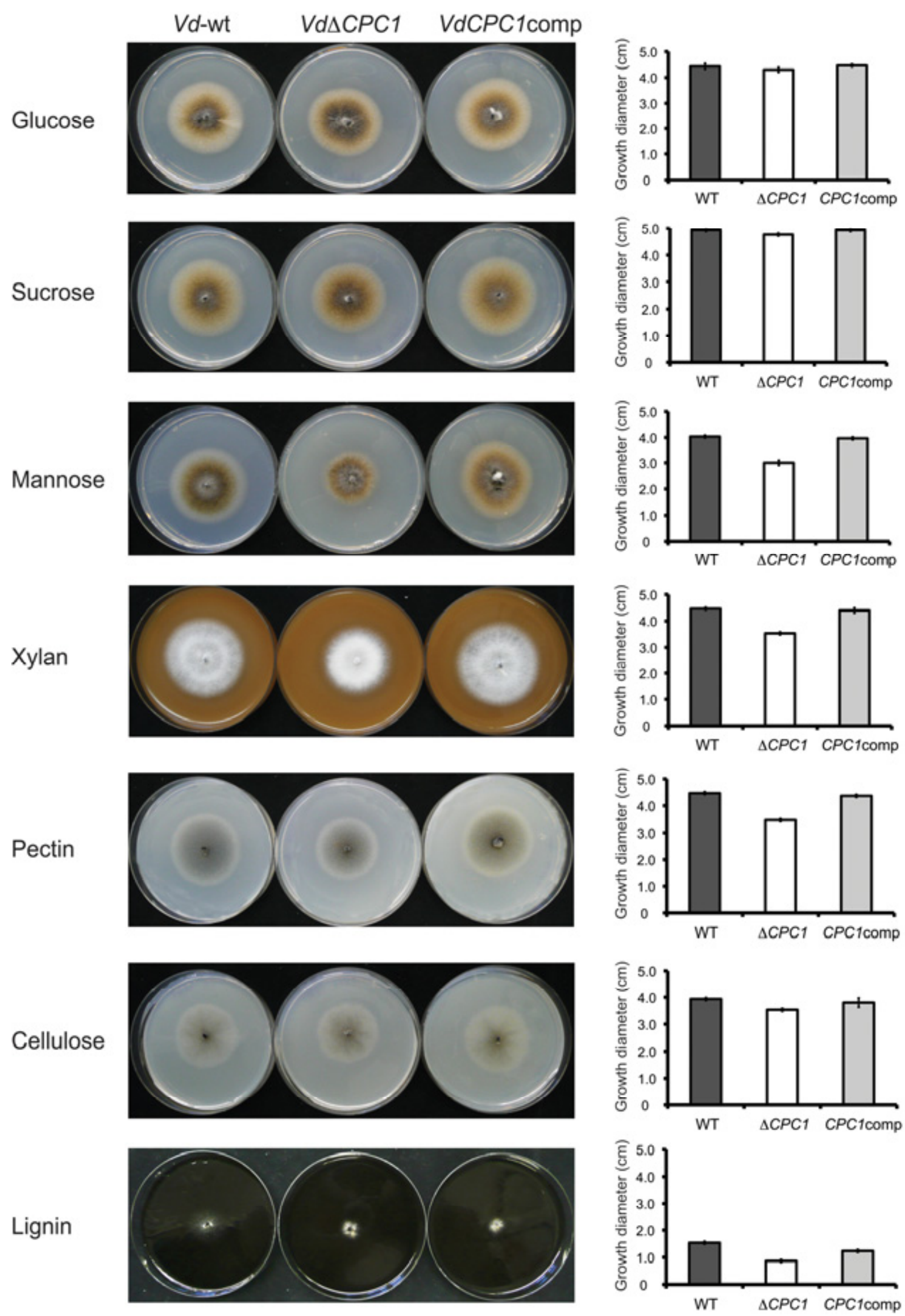

Fig. 4. Growth of the Verticillium dahliae wild type ( $V d$-wt) or the $V d C P C 1$ deletion mutant $(V d \triangle C P C 1)$ on different carbon sources. Czapek Dox agar was used for growth tests with either sucrose or the indicated carbon sources. Diameters of colonies were measured and compared between the wild type and the mutant 10 days after inoculation. 
Disease symptoms decrease significantly when plants are infected with the $C P C 1$ mutant fungi.

We evaluated whether the cross-pathway regulator protein Cpc1 is contributing to plant pathogenicity. The silenced $V$. longisporum mutant $(V l C P C 1 \mathrm{sm})$, which provides a residual transcriptional $C P C 1$ activity, as well as the $V$. dahliae deletion mutant $(V d \triangle C P C 1)$, lacking any Cpc1 protein, were analyzed in their respective hosts for the induction of fungal-caused dis-

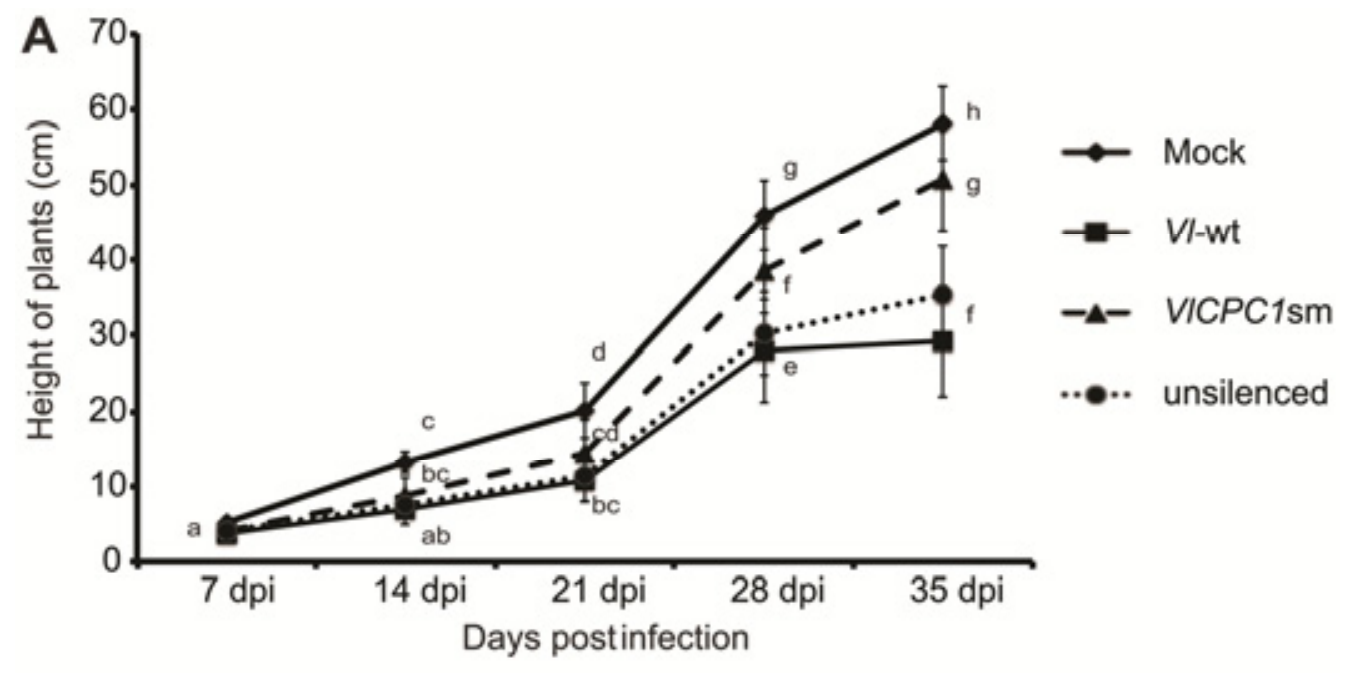

B
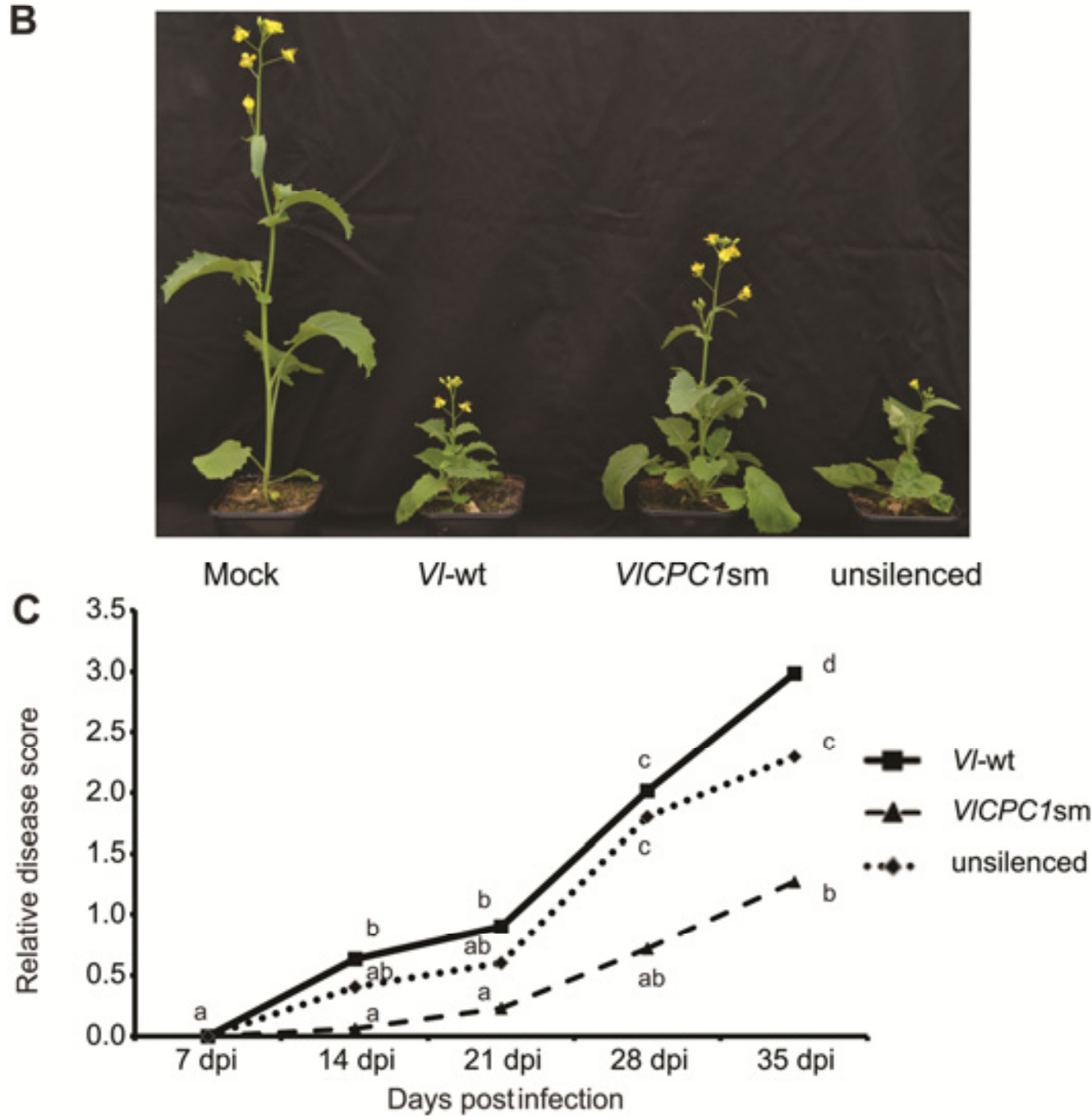

Fig. 5. Assessment of pathogenicity of the VlCPCl-silenced mutant in the plant host Brassica napus. A, Verticillium longisporum induced stunting of B. napus plants after infection. Each point represents the average height of 30 oilseed rape plants, either uninfected (mock inoculated with tap water) or infected with the wild-type fungus $(\mathrm{Vl}$-wt) or the $\mathrm{VlCPCl}$-silenced mutant $(\mathrm{VlCPC} / \mathrm{sm})$ or a nonsilenced mutant (unsilenced). Plants were measured at indicated days postinfection (dpi) until a significantly marked degree of the disease was visible at 35 dpi. B, Examples of uninfected or infected B. napus plants at 35 dpi. C, Assessment of disease development by scoring for disease symptoms according to Eynck and associates (2007). Plants were scored for disease symptoms at the indicated dpi. The data represent average values \pm standard deviations of 30 experimental replicates. Different letters indicate significant differences at $P<0.05$. 
ease symptoms, such as stunted host plants or signs of early senescence (Figs. 5 and 6).

The silenced $V$. longisporum was analyzed in 1-week-old oilseed rape Brassica napus that was infected by root-dip inocu- lation. Wild-type infection resulted in clearly visible disease symptoms after 21 days postinfection (dpi), when the disease further accelerates and becomes even more distinctive at later time points (Fig. 5A and B). Plant height was measured weekly
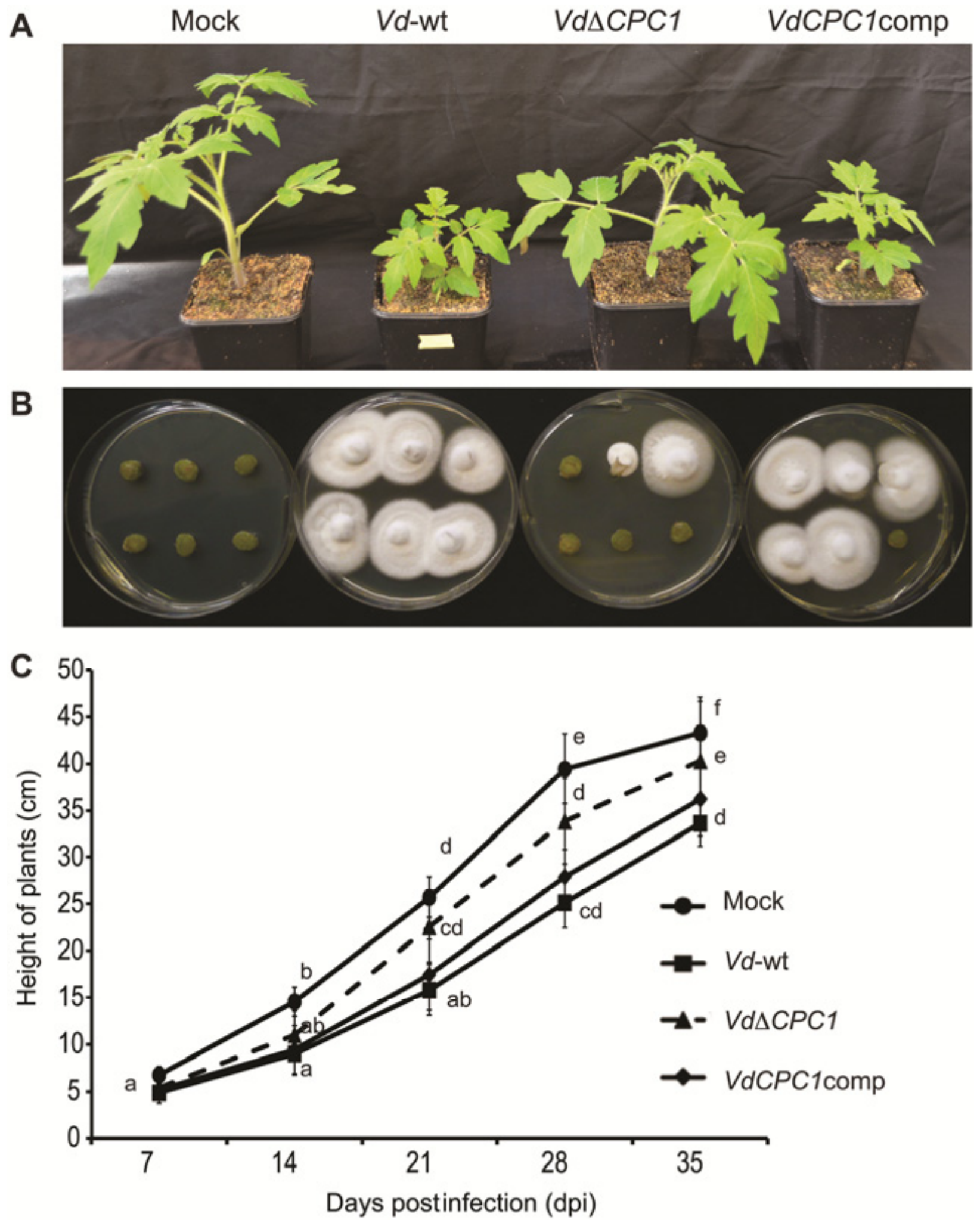

Fig. 6. Assessment of pathogenicity of the $V d C P C l$ deletion mutant. A, Tomato infection assay. Representative Solanum lycopersicum plants were shown at 21 dpi. B, Fungal regrowth test. Image of fungal colonies growing on PDA plates from tomato stem pieces infected with the Verticillium dahliae wild type or the $V d C P C 1$ knockout mutant. Stem pieces of mock plants were served as control. C. Assessment of stunting symptom of $S$. lycopersicum due to V. dahliae infection. The height of tomato plants infected with the wild type ( $V d$-wt) and the mutant $V d \triangle C P C 1$ was measured at 7, 14, 21, 28 and 35 dpi. For comparison, the height of tomato plants inoculated with tap water (mock) was used as control. The plants show symptoms after $21 \mathrm{dpi}$. The data represent average values \pm standard deviations of 20 experimental replicates. Different letters indicate significant differences at $P<0.05$. 
after inoculation, and infected oilseed rape plants were scored for senescence disease symptoms by several parameters, including the monitoring of yellowing and death of the leaves. Disease scores from 1 to 9 represent the range between asymptomatic to dead plants (Eynck et al. 2007). Disease symptoms had to be distinguished from natural senescence and, therefore, yellowing of leaves in the uninfected mock plants was monitored for comparison. The silenced mutant $(\mathrm{VlCPClsm})$ showed alreadyreduced disease scores in comparison with the $V$. longisporum wild type in the initial phase of the disease at 21 dpi (Fig. 5C). In contrast to the wild type, the silenced mutant showed no acceleration, but rather, a slowdown of the disease, which is reflected in the lower slope in the relative disease scores between 21 and 35 dpi. In comparison, an unsilenced strain showed an infection pattern similar to $V$. longisporum wild type. Further analysis showed pathogenicity related changes in plant leaves. At 21 days after infection, the $C P C l$-silenced mutant showed, on average, fewer leaves than wild type-infected plants with a larger leaf size. In addition, infected plants showed more leaves per node, resulting in an increased verticilliate shape of the plant (Supplementary Fig. S6).

The reduction of pathogenicity of the silenced mutant of $V$. longisporum resulting in a mild version of the disease correlates with the residual reduced $C P C 1$ trancriptional activity.
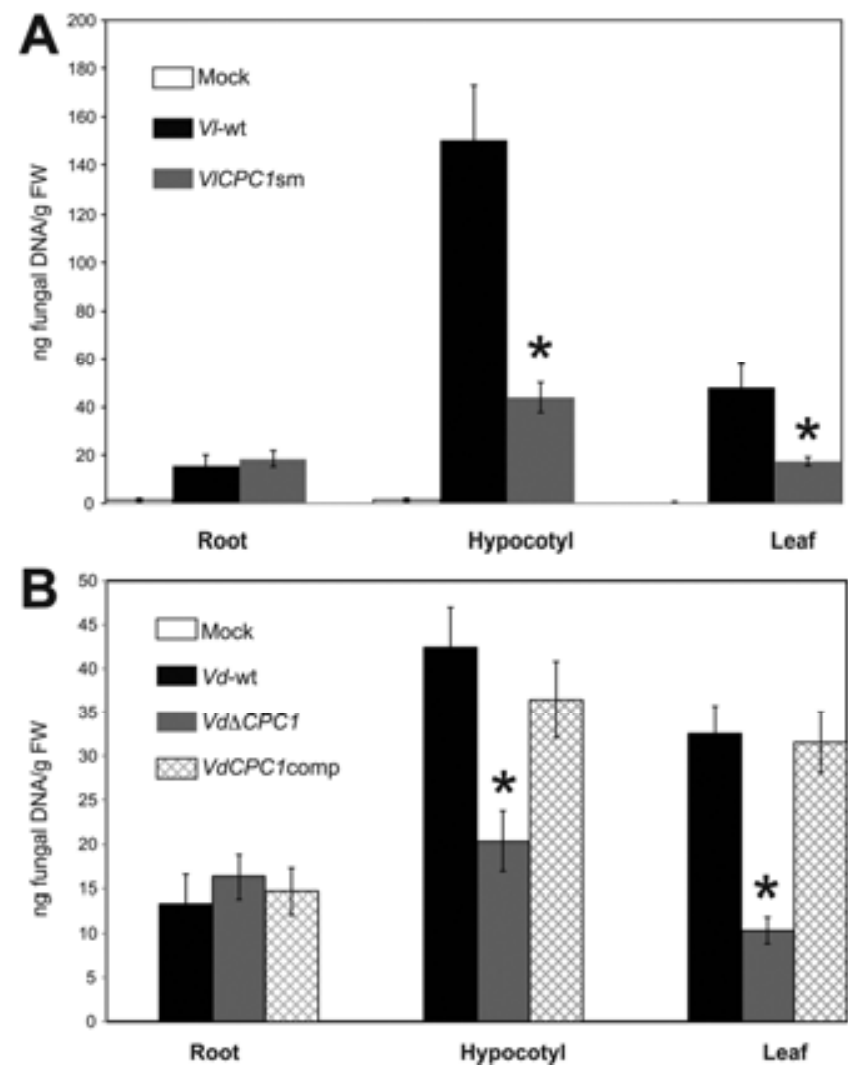

Fig. 7. Infection assay and determination of Verticillium longisporum and $V$. dahliae DNA concentration in hypocotyls of infected plants after 35 days postinfection (dpi). Fungal DNA was measured with real-time polymerase chain reaction. A, Roots, hypocotyls, and leaves of oilseed rape Brassica napus infected with the VlCPCl-silenced mutant $(V l C P C 1 \mathrm{sm})$ and $\mathrm{V}$. longisporum wild type ( $\mathrm{Vl}$-wt). B, Roots, hypocotyls, and leaves of tomato Solanum lycopersicum infected with VdCPC1 knockout mutant $(V d \triangle C P C 1)$ and $V$. dahliae wild type $(V d$-wt) at $35 \mathrm{dpi}$. The data represent average values \pm standard deviations of five experimental replicates. The tap water-inoculated plants (mock) as a control did not show the presence of any $V$. longisporum or $V$. dahliae DNA. ng DNA/g FW = nanograms of $V$. longisporum or $V$. dahliae DNA per gram of fresh weight of plant tissue. Significant differences between the wild type and mutants are illustrated by asterisks, which indicate $P \leq 0.05$.
For a more comprehensive picture of the role of the $\mathrm{Cpc1}$ protein, deletion mutants of $V$. dahliae lacking any $C P C 1$ transcription were analyzed in tomato plants. Solanum lycopersicum was root-dipped for infection with $V$. dahliae $\triangle C P C 1$ mutant or wild type. The $V$. dahliae wild type caused the typical symptoms on tomato, including stunting and chlorosis. Similar to the infection of the silenced $V$. longisporum strain, the $C P C 1$ deletion mutant $(V d \triangle C P C l)$ showed strongly reduced pathogenicity with less stunting symptoms (Fig. 6A). Both data sets support the hypothesis that the gene for the $\mathrm{Cpc1}$ regulator of the cross-pathway control of amino-acid biosynthesis is required for Verticillium species as vascular plant pathogens to cause plant disease.

The plant vascular system might provide amino-acid starvation conditions for the fungi. Therefore, fungal colonization of the wild type and the mutant in planta were monitored and compared. Fungal DNA of mutants and wild types of $V$. longisporum in B. napus or $V$. dahliae in tomato were quantified in the plant tissues by real-time PCR. All wild types and mutant fungi were monitored, with low and similar amounts of fungal DNA in roots of the corresponding infected plants, suggesting that this initial phase of colonization does not require an intact crosspathway control (Fig. 7). Silencing of the two VlCPCl isogenes was still stable in the oilseed rape after 35 dpi. Highest concentrations of fungal wild-type DNAs were normally present in the hypocotyls of infected plants. $C P C 1$ knockdowns or knockouts showed significantly less fungal $V l C P C l \mathrm{sm}$ or $V d \triangle C P C l$ DNA when the infected hypocotyls were compared with wild types after $35 \mathrm{dpi}$. The DNA content of $V d \triangle C P C 1$ in tomato hypocotyls was reduced by $40 \%$ and the DNA content of $V l C P C l \mathrm{sm}$ in B. napus hypocotyls was even reduced by $80 \%$ (Fig. 7).

These data demonstrate that the reduced pathogenicity of the $C P C 1$ mutant strains is not due to a defect in the initial root colonization of the plant but is due to reduced growth in the plant hypocotyls. This suggests that the fungi encounter amino acid-starvation conditions in the hypocotyls, which have to be counteracted by a functional cross-pathway control of amino acids.

\section{DISCUSSION}

It was anticipated that, for plant-pathogenic fungi, a knockdown or knockout of $C P C 1$ might reduce pathogenicity (Shen and Ebbole 1997), but this hypothesis was not verified so far. Knockdowns in $V$. longisporum and knockouts in $V$. dahliae represent the first examples of phytopathogenic fungi, which require the amino-acid regulatory gene $C P C l$ for infection and colonization of their respective host plants. This situation is similar to human fungal pathogens like A. fumigatus, in which mutants impaired in the cross-pathway control system had strongly reduced pathogenicity, and the regulatory gene $C p c A$ contributes in effectively establishing pulmonary aspergillosis (Abad et al. 2010; Krappmann et al. 2004; Sasse et al. 2008).

The cross-pathway control is a complex global regulatory network that regulates the synthesis of amino acids in numerous fungi. The cross-pathway control has been the subject of examination in several filamentous fungi, including $A$. nidulans (Hoffmann et al. 2001; Piotrowska et al. 1980), A. niger (Wanke et al. 1997), A. fumigatus (Krappmann et al. 2004; Sasse et al. 2008), Candida albicans (Tripathi et al. 2002), Magnaporthe grisea (Shen and Ebbole 1997), N. crassa (Carsiotis et al. 1974; Paluh et al. 1988), and F. fujikuroi (Schönig et al. 2009). In yeast, the same system was named general control (Hinnebusch 1984; Natarajan et al. 2001). Amino acid-starvation conditions activate this system, resulting in derepression of the cross-pathway control gene GCN4 in yeast or CpcA/ $C p c l$ in filamentous fungi. In yeast, the amount of Gen4 in the 
cell is regulated primarily by a translational control (Albrecht et al. 1998; Braus 1991; Irniger and Braus 2003). There is an additional amino acid starvation-induced transcriptional autoactivation present in filamentous fungi that had been originally described in A. nidulans (Hoffmann et al. 2001). The presence of the corresponding Cpc1 upstream DNA-binding element in the promoters of the Verticillium CPCl regulatory genes and the finding that a bradytrophic aromatic amino-acid mutant showed increased VlCPCl transcription (Singh et al. 2010) suggests that this transcriptional autocontrol mechanism is conserved in vascular plant pathogens.

In addition to its role as amino-acid regulator, the crosspathway control regulator $\mathrm{Gcn} 4 / \mathrm{CpcA} / \mathrm{Cpc} 1$ has various distinct morphological functions in fungi. Gen4 controls starvationinduced adhesive and pseudohyphal growth in the yeast $S$. cerevisiae (Braus et al. 2003; Herzog et al. 2011; Valerius et al. 2007). Similarly, histidine starvation controls the homolog CaGcn 4 of $C$. albicans, which is involved in morphogenetic responses (Tripathi et al. 2002). In A. nidulans, the amino acid starvation-induced cross-pathway control can block fruiting body formation as a complex cellular differentiation process (Hoffmann et al. 2000).

During colonization and infection, $V$. longisporum occupies the xylem vessels of the oilseed crop B. napus. The composition of xylem sap consists of water, inorganic compounds, organic acids, and amino acids (Kehr et al. 2005; Sakuta et al. 1998). A reduced activity of the Vlaro2 isogenes encoding the aromatic amino-acid biosynthetic enzyme chorismate synthase resulted in reduced pathogenicity and was the first hint that the xylem sap does not provide an appropriate composition of aromatic amino acids for fungal growth (Singh et al. 2010). In this study, we present a $V$. longisporum mutant strain that lacks $C P C l$ but has an intact basal transcription of amino-acid biosynthetic genes that is sufficient to grow on plates in the absence of any amino acid. The strain is deficient in the transcriptional control of aminoacid biosynthetic genes, which allows an increased transcription during an imbalanced supply of amino acids. This mutant strain is unable to efficiently colonize the plant host hypocotyl, which results in a significantly reduced pathogenicity. $V l C P C l$ seems to aid in the growth of the fungus in the xylem vessels, in which amino acids are scarce. Acquiring nutrient sources from its host is crucial for a fungal pathogen (Gibson et al. 2011; King et al. 2011). The mutant strain does not reach the upper parts of the plants in later phases of infection. Consistently, different plant tissues, especially hypocotyls, stems, and leaves showed significantly reduced amounts of DNA for the mutant as compared with the $V$. longisporum wild-type strain. The mutant strain is able to infect the plant but is not capable of successfully growing in the upper parts of the host (Fig. 7). Based on our results, this might be due to a limited nutritional supply of the mutant strain with appropriate amounts of amino acids. Accordingly, plants infected with the silenced mutant are considerably stronger and look healthier than plants infected with the wildtype strain.

B. napus xylem sap probably provides not only nutrition to $V$. longisporum but may also contain certain factors, such as phytohormones, for plant defense against $V$. longisporum. Xylem sap is the medium for cross-talk between the pathogen, $V$. longisporum, and its host, B. napus. Infection of model plant Arabi- dopsis thaliana by $V$. longisporum induces, in roots, specific tryptophan-derived metabolites, such as indole-3-carboxylic acid and the phytoalexin camalexin. Camalexin is an efficient inhibitor of Verticillium growth (Iven et al. 2012; Ratzinger et al. 2009; Singh et al. 2010, 2012). These results support the theory that $C P C 1$ of $V$. longisporum and $V$. dahliae might also have an influence on secondary metabolism, which might interfere with the communication between fungus and its host. Several researchers describe an impact of the cross-pathway regulator on secondary metabolism (Abad et al. 2010; Elliott et al. 2011). In A. nidulans, CpcA suppresses the biosynthesis of penicillin and other secondary metabolites under amino-acid starvation. For Leptosphaeria maculans, silencing of the CpcA homolog gene increases, either directly or indirectly, the production of the toxin sirodesmin. In contrast, $\mathrm{Cpc} 1$ of $F$. fujikuroi is not involved in the glutamine synthetase-dependant regulation of secondary metabolism (Schönig et al. 2009). One possible explanation why the $C P C l$ genes of $V$. longisporum or $V$. dahliae contribute to plant pathogenicity is that the cross-pathway system allows counteracting an unbalanced amino acid supply. The amino-acid composition of the xylem fluid might correspond to an unequal amino-acid diet for fungal nutrition. Another explanation is a disturbed communication between fungus and host due to a role of $C P C 1$ in the control of secondary metabolism. Finally, $C P C 1$ might also be important for both the nutrition in the plant and the correct interplay in exchanging secondary metabolite signals between fungus and host-plant.

\section{MATERIALS AND METHODS}

\section{Strains, media, and growth conditions.}

All Verticillium strains used are listed in Table 2. The simulated xylem fluid medium (SXM) (Neumann and Dobinson 2003) contained sodium polypectate ( $2 \mathrm{~g}$ per liter), casein hydrolysate (4 g per liter), $1 \mathrm{M}$ magnesium sulphate $(2 \mathrm{ml}$ per liter), 50× AspA solution (20 ml per liter) and $1,000 \times$ trace elements ( $1 \mathrm{ml}$ per liter). CDA contained sucrose (30 g per liter), $1 \mathrm{M}$ magnesium sulphate (2 ml per liter), 50× AspA solution (20 ml per liter), and ferrous sulphate ( $0.01 \mathrm{~g}$ per liter). Potato dextrose agar was purchased from Sigma Aldrich and was used according to the manufacturer's description. Czapek Dox broth medium was inoculated with $V$. longisporum or $V$. dahliae spores and was incubated at $25^{\circ} \mathrm{C}$ for 10 days in the dark to generate fungal spore suspension stock. The spores were counted using a Thoma-chamber (Optik Labor, Lancing, U.K.), were adjusted to $1 \times 10^{6}$ spores per milliliter, and were preserved as $30 \%$ glycerol stock at $-80^{\circ} \mathrm{C}$.

Escherichia coli $\mathrm{DH} 5 \alpha$ cells were grown at $37^{\circ} \mathrm{C}$ for propagation of plasmids in Luria-Bertani (LB) broth or on LB plates supplemented with ampicillin ( $100 \mu \mathrm{g}$ per milliliter), phleomycin $(50 \mu \mathrm{g}$ per milliliter), or kanamycin (100 $\mu \mathrm{g}$ per milliliter). The Agrobacterium tumefaciens AGL-1 strain (Lazo et al. 1991) was used for plasmid maintenance for transformation of $V$. longisporum in LB medium supplemented with kanamycin (100 $\mu \mathrm{g}$ per milliliter) at $28^{\circ} \mathrm{C}$.

\section{Southern hybridization and DNA isolation.}

Southern hybridization analyses (Southern 1975) were performed with genomic DNA of $V$. longisporum extracted from

Table 2. Verticillium isolates used in this study

\begin{tabular}{|c|c|c|c|c|}
\hline Isolate & Species & Host & Geographic origin & Reference \\
\hline V143 & Verticillium longisporum & Brassica napus (oilseed rape) & Mecklenburg/Germany & Zeise and von Tiedermann, 2001 \\
\hline Vd73 & V. dahliae & Linum usitatissimum (linseed) & Mecklenburg/Germany & Zeise and von Tiedermann, 2001 \\
\hline VdJR2 & V. dahliae & Solanum lycopersicum (tomato) & Canada & Fradin et al., 2009 \\
\hline Va1 & V. albo-atrum & Solanum tuberosum (potato) & Wiconsin/USA & Zeise and von Tiedermann, 2002b \\
\hline
\end{tabular}


powdered mycelium (Kolar et al. 1988), using primers ProbeCPC1-L and ProbeCPC1-R, described in Table 1, for PCR. The 521-bp PCR fragment of the $C P C l$ gene was purified with QIAquick gel extraction kit (Qiagen, Hilden, Germany) and was labeled as probe, using Amersham AlkPhos Direct labeling reagents (GE Healthcare, Munich).

\section{Cloning and sequencing of $C P C 1$.}

$C P C 1$ genes were PCR-amplified from genomic DNA of the haploid V. dahliae, V. albo-atrum, and the hybrid V. longisporum, with an optimized procedure for the hybrid (Tran et al. 2013). The PCR products were purified with QIAprep spin miniprep kit (Qiagen) for direct sequencing or were cloned into pJET1.2 vector (Fermentas, St. Leon-Rot, Germany) for transformation of $E$. coli DH5 $\alpha$. For plasmid DNA extraction, 20 positive colonies were chosen. DNA sequencing was performed by G2L, Göttingen, Germany.

\section{Silencing of $C P C 1$ isogenes in $V$. longisporum.}

pME3988 was constructed for silencing of the VlCPC1 isogenes. A 544-bp fragment present in both $V l C P C 1$ isogenes was amplified from cDNA by PCR with primers $V l C P C l$ gate- $\mathrm{L}$ and $V l C P C l$ gate-R and was integrated into the $\mathrm{pDONR} / \mathrm{Zeo}$ plasmid (Invitrogen, Karlsruhe, Germany) with BP clonase (Invitrogen). The resulting recombinant plasmid was mixed in the presence of LR clonase (Invitrogen) with a modified silencing vector pGS1 based on pSilent1 (Nakayashiki et al. 2005), pPK2 (Covert et al. 2001), and gateway cassettes (Invitrogen). LR clonase promotes the integration of the VlCPCl fragment in both sense and antisense directions of the silencing vector. The resulting plasmid, pME3988, harbors a T-DNA (transfer DNA) containing the hygromycin resistance gene as selection marker and the VlCPCl silencing cassette-including the TrpC promoter, VlCPCl sense, spacer, and VlCPCl antisense-TrpC terminator (Supplementary Fig. S7A). pME3988 was transformed into Agrobacterium tumefaciens AGL-1 according to Lazo and associates (1991) and was selected on LB medium plates containing kanamycin (100 $\mu \mathrm{g}$ per milliliter). The T-DNA of the silencing construct was transferred into the genome of $V$. longisporum by Agrobacterium tumefaciens-mediated transformation (Mullins et al. 2001). For cocultivation of the Agrobacterium tumefaciens carrying the construct and $V$. longisporum spore suspension, 85-mm filter paper (Sartorius, Göttingen, Germany) was used. Stable transformants were grown on medium lacking hygromycin B for five generations and were then plated on selective medium supplemented with $100 \mu \mathrm{g}$ per milliliter of hygromycin $\mathrm{B}$, in which only mitotically stable transformants could grow (Singh et al. 2010). The efficiency of VlCPCl silencing in the transformants was determined by quantitative real-time PCR in comparison to the $V$. longisporum wild type.

\section{Deletion of $C P C 1$ in the haploid $V$. dahliae.}

Plasmid pKOCPC1 was constructed on the basis of the binary vector pPK2 (Covert et al. 2001), with a nourseothricin resistance cassette to delete a single $C P C 1$ of $V$. dahliae $(V d C P C 1)$. It includes two PCR fragments of $1.6 \mathrm{~kb}$ and $866 \mathrm{bp}$, covering the $V d C P C 1$ gene from the $V$. dahliae JR2 genome with a deletion of $252 \mathrm{bp}$ in the open reading frame, which were amplified using primer pairs $V d C P C 1 \mathrm{KOF} 1-\mathrm{L} /$ $V d C P C 1 \mathrm{KOF} 1-\mathrm{R}$ and $V d C P C 1 \mathrm{KOF} 2-\mathrm{L} / V d C P C 1 \mathrm{KOF} 2-\mathrm{R}$, respectively. The primers contain restriction sites for $\mathrm{PacI} / \mathrm{SacI}$ or XbaI/HindIII at the $5^{\prime}$ ends to facilitate cloning of the PCR products. pKOCPCl was introduced into Agrobacterium tumefaciens AGL-1 for fungal transformation of the $V$. dahliae JR2 strain (Table 2), and $V d C P C l$ deletion mutants were screened by PCR using genomic DNA, before being confirmed by Southern hybridization (Supplementary Fig. S8).
Complementation of $\triangle C P C 1$ strain in V. dahliae.

Plasmid pKOCPClComp was constructed on the basis of the binary vector pPK2 (Covert et al. 2001). It includes the full-length sequence of the $V d C P C l$ gene from the $V$. dahliae JR2 genome, which was amplified using primer pair $V d C P C 1 \mathrm{KOF} 1-\mathrm{L} / V d C P C 1 \mathrm{KOF} 2-\mathrm{R}$. The primers contain restriction sites for $P a c \mathrm{I} / \mathrm{XbaI}$ at the $5^{\prime}$ ends to facilitate cloning of the PCR products. pKOCPClComp was introduced into Agrobacterium tumefaciens AGL-1 for fungal transformation of the $V$. dahliae JR2 strain (Table 2).

\section{Phenotypic analysis of VICPC1 silenced mutants.}

Verticillium longisporum wild type and the mutant strains were grown on CDA with or without $5 \mathrm{mM} 5$-MT for 4 days at $25^{\circ} \mathrm{C}$. The analog induces a false-feedback inhibitor, trypthophan starvation. Colony diameters were measured after 3, 6, 9, 12 , and $15 \mathrm{dpi}$. For investigation of $\mathrm{VlCPCl}$ expression, Czapek Dox broth was inoculated with the $V$. longisporum wild type and the silenced mutant $V l C P C l \mathrm{sm}$, for 7 days at $25^{\circ} \mathrm{C}$. After that timepoint, half of the cultures was used as control whereas the other half was induced with $5 \mathrm{mM} 5-\mathrm{MT}$, and the cultures were incubated for an additional $4 \mathrm{~h}$ at $25^{\circ} \mathrm{C}$.

\section{Plant infection assay.}

One-week-old $B$. napus seedlings were inoculated with $1 \times$ $10^{6}$ spores per milliliter of V1CPC1sm or wild-type fungus (V143) or with sterile tap water as mock inoculation for $30 \mathrm{~min}$ by the root-dipping method. Seedlings were transferred in pots filled with sterile sand and soil (1:1) mixture and were incubated in a climate chamber with $14 \mathrm{~h}$ of light at $23^{\circ} \mathrm{C}$ and $10 \mathrm{~h}$ of dark at $20^{\circ} \mathrm{C}$. The plants were cultivated until 35 dpi. The inoculated plant heights were measured and disease symptoms were scored (Eynck et al. 2007).

Ten-day-old tomato seedlings were inoculated with $1 \times 10^{6}$ fungal spores per milliliter (mutants or wild type) or mock with tap water for $30 \mathrm{~min}$ by root-dipping (Fradin et al. 2009). Seedlings were transferred in pots with a sterile sand and soil $(1: 1)$ mixture. Plants were cultivated in a greenhouse with $16 \mathrm{~h}$ of light at $23^{\circ} \mathrm{C}$ and $8 \mathrm{~h}$ of dark at $20^{\circ} \mathrm{C}$. Plant heights were measured at 7, 14, 21, 28, and 35 dpi. In addition, the leaf size of the third leaf was measured, the number of leaves per plant was counted, and the verticilliate shape of the plants was scored starting at $21 \mathrm{dpi}$. The verticilliate shape was scored from $0=$ no effect (corresponding to uninfected plants) to $3=$ strong effect. For each infection assay, 60 plants per treatment were inoculated. The experiments were repeated two times.

\section{Quantification of Verticillium DNA and RNA by real-time PCR.}

Hypocotyls were separated from the infected oilseed rape plants harvested at $35 \mathrm{dpi}$. A sample of 20 single plants was harvested from each treatment. For relative quantification of RNA, VICPC1 cDNA was amplified with the primer pair $C P C 1$ RT1/CPC1-RT2; the primers amplify a part of the b-ZIP leucine zipper domain and the histone gene as reference for normalization with the primer pair $H 2 A-\mathrm{RT} 1 / H 2 A$-RT2 (Table $1)$. The data were analyzed using the $2-\Delta \Delta \mathrm{Ct}$ relative quantification method (Livak and Schmittgen 2001). For absolute quantification of DNA, fungal DNA from plants was quantified using the primer pair OLG70/OLG71 for amplification of a specific Verticillium fragment of rDNA (parts of the 5.8S rRNA gene and ITS2) (Eynck et al. 2007). For each treatment, 25 ng of DNA was used as starting material.

Total RNA was isolated from fungal mycelium of $V$. longisporum, $V$. dahliae, or the corresponding mutants grown in SXM using the RNeasy plant mini kit (Qiagen). The cultures were inoculated with a spore suspension of $1 \times 10^{6}$ spores per 
milliliter and were cultivated for 5 days at $25^{\circ} \mathrm{C}$. The concentration of RNA samples was measured with a NanoDropND1000 spectrophotometer (PeqLab, Erlangen, Germany). Total RNA $(1 \mu \mathrm{g})$ was transcribed into cDNA, using the QuantiTect reverse transcription kit (Qiagen). Gene expression was measured by real-time PCR using a specific primer pair. Reactions contained $2 \mu \mathrm{l}$ of each $0.5 \mu \mathrm{M}$ primer $(H 2 A-\mathrm{RT} 1$ and H2A-RT2 or CPC1-RT1 and CPC1-RT2 [Table 1]), $1 \mu \mathrm{l}$ of the cDNA, and reverse transcriptase-grade PCR water to a final volume of $11 \mu \mathrm{l}$. To obtain a final volume of $20 \mu \mathrm{l}$ per reaction, 5 PRIME MasterMix (5 PRIME GmbH, Hamburg, Germany) was added. Each reaction was run in triplicates for all samples. Reactions were run under the following conditions, using the Light Cycler 2.0 System (Roche, Manheim, Germany): $95^{\circ} \mathrm{C}$ denaturation for $3 \mathrm{~min}, 42$ cycles at $95^{\circ} \mathrm{C}$ for $10 \mathrm{~s}$, $63^{\circ} \mathrm{C}$ for $15 \mathrm{~s}$, and $72^{\circ} \mathrm{C}$ for $25 \mathrm{~s}$ to calculate cycle threshold values, followed by $63^{\circ} \mathrm{C}$ for $15 \mathrm{~s}$ with a continuous increase of temperature by $0.1^{\circ} \mathrm{C}$ each cycle up to $95^{\circ} \mathrm{C}$ to obtain a melting curve. Standard curves were produced with purified genomic DNA products of 0.1 to $100 \mathrm{ng}$ per microliter. Absolute amounts of genomic DNA were calculated using a correlation coefficient formula generated from the standard curve.

For relative quantification of RNA, cDNA of amino-acid metabolism genes was amplified with primer pairs Arg6RT1L/ Arg6RT1R, Leu4RT1L/Leu4RT1R, Lys1RT1L/Lys1RT1R, and Trp5RT1L/Trp5RT1R. The histone gene was used as reference for normalization with the primer pair $H 2 A-\mathrm{RT} 1 / H 2 A-\mathrm{RT} 2$ (Table 1).

\section{Phylogenetic analysis of $C P C 1$ genes.}

The phylogenetic trees were constructed with the MEGA 5.0 software (Tamura et al. 2011) based on the neighbor-joining method (Saitou and Nei 1987). The statistical reliabilities of the internal branches were assessed for all trees by using the bootstraps of 1,000 replicates. The $p$-distance model was used and gaps or missing data were treated with pairwise deletion (Tran et al. 2013).

\section{ACKNOWLEDGMENTS}

We are grateful to A. Polle for providing greenhouse space, M. FrankeKlein for excellent support during the plant infection, and support by I. Feussner and his lab. This work was funded by the German Research Foundation (DFG) grant FOR546 and the Federal Ministry of Education and Research (BMBF) BioFung project.

\section{LITERATURE CITED}

Abad, A., Fernandez-Molina, J. V., Bikandi, J., Ramirez, A., Margareto, J., Sendino, J., Hernando, F. L., Ponton, J., Garaizar, J., and Rementeria, A. 2010. What makes Aspergillus fumigatus a successful pathogen? Genes and molecules involved in invasive aspergillosis. Rev. Iberoam. Micol. 27:155-182.

Albrecht, G., Mösch, H. U., Hoffmann, B., Reusser, U., and Braus, G. H. 1998. Monitoring the Gcn4 protein-mediated response in the yeast Saccharomyces cerevisiae. J. Biol. Chem. 273:12696-12702.

Braus, G. H. 1991. Aromatic amino acid biosynthesis in the yeast Saccharomyces cerevisiae: A model system for the regulation of a eukaryotic biosynthetic pathway. Microbiol. Rev. 55:349-370.

Braus, G. H., Grundmann, O., Brückner, S., and Mösch, H. U. 2003. Amino acid starvation and Gcn $4 p$ regulate adhesive growth and FLO11 gene expression in Saccharomyces cerevisiae. Mol. Biol. Cell 14:4272-4284.

Carsiotis, M., and Jones, R. F. 1974. Cross-pathway regulation: Tryptophan-mediated control of histidine and arginine biosynthetic enzymes in Neurospora crassa. J. Bacteriol. 119:889-892.

Carsiotis, M., Jones, R. F., and Wesseling, A. C. 1974. Cross-pathway regulation: Histidine-mediated control of histidine, tryptophan, and arginine biosynthetic enzymes in Neurospora crassa. J. Bacteriol. 119:893-898.

Covert, S. F., Kapoor, P., Lee, M., Briley, A., and Nairn, C. J. 2001. Agrobacterium tumefaciens-mediated transformation of Fusarium circina- tum. Mycol. Res. 105:259-264.

Daebeler, F., Amelung, D., and Zeise, K. 1988. Verticillium-Welke an winterraps auftreten und bedeutung. nachrichtenblatt Pflanzenschutzdienst DDR 42:71-73.

Eckert, S. E., Kubler, E., Hoffmann, B., and Braus, G. H. 2000. The tryptophan synthase-encoding trpB gene of Aspergillus nidulans is regulated by the cross-pathway control system. Mol. Gen. Genet. 263:867876.

Elliott, C. E., Fox, E. M., Jarvis, R. S., and Howlett, B. J. 2011. The crosspathway control system regulates production of the secondary metabolite toxin, sirodesmin PL, in the ascomycete, Leptosphaeria maculans. BMC Microbiol. 11:169.

Eynck, C., Koopmann, B., Grunewaldt-Stoecker, G., Karlovsky, P., and von Tiedemann, A. 2007. Differential interactions of Verticillium longisporum and $V$. dahliae with Brassica napus detected with molecular and histological techniques. Eur. J. Plant Pathol. 118:259-274.

Floerl, S., Majcherczyk, A., Possienke, M., Feussner, K., Tappe, H., Gatz, C., Feussner, I., Kues, U., and Polle, A. 2012. Verticillium longisporum infection affects the leaf apoplastic proteome, metabolome, and cell wall properties in Arabidopsis thaliana. PLoS One 7:e31435.Published online.

Gibson, D. M., King, B. C., Hayes, M. L., and Bergstrom, G. C. 2011. Plant pathogens as a source of diverse enzymes for lignocellulose digestion. Curr. Opin. Microbiol. 14:264-270.

Günzelmann, H., and Paul, V. H. 1990. Zum auftreten und zur bedeutung der verticillium-welke an raps in der bundesrepublik deutschland in 1989. Raps 8:23-25.

Heale, J. B., and Karapapa, V. K. 1999. The Verticillium threat to Canada's major oilseed crop: Canola. Can. J. Plant Pathol. 21:1-7.

Herzog, B., Streckfuss-Bomeke, K., and Braus, G. H. 2011. A feedback circuit between transcriptional activation and self-destruction of Gcn4 separates its metabolic and morphogenic response in diploid yeasts. J. Mol. Biol. 405:909-925.

Hinnebusch, A. G. 1984. Evidence for translational regulation of the activator of general amino acid control in yeast. Proc. Natl. Acad. Sci. U.S.A. 81:6442-6446.

Hinnebusch, A. G. 1986. The general control of amino acid biosynthetic genes in the yeast Saccharomyces cerevisiae. CRC Crit. Rev. Biochem. 21:277-317.

Hinnebusch, A. G., and Natarajan, K. 2002. Gcn4p, a master regulator of gene expression, is controlled at multiple levels by diverse signals of starvation and stress. Eukaryot. Cell 1:22-32.

Hoffmann, B., Wanke, C., Lapaglia, S. K., and Braus, G. H. 2000. c-Jun and RACK1 homologs regulate a control point for sexual development in Aspergillus nidulans. Mol. Microbiol. 37:28-41.

Hoffmann, B., Valerius, O., Andermann, M., and Braus, G. H. 2001. Transcriptional autoregulation and inhibition of mRNA translation of amino acid regulator gene cpcA of filamentous fungus Aspergillus nidulans. Mol. Biol. Cell 12:2846-2857.

Inderbitzin, P., Davis, R. M., Bostock, R. M., and Subbarao, K. V. 2011. The ascomycete Verticillium longisporum is a hybrid and a plant pathogen with an expanded host range. PLoS One 6:e18260. Published online.

Irniger, S., and Braus, G. H. 2003. Controlling transcription by destruction: The regulation of yeast Gcn4p stability. Curr. Genet. 44:8-18.

Iven, T., König, S., Singh, S., Braus-Stromeyer, S. A., Bischoff, M., Tietze, L. F., Braus, G. H., Lipka, V., Feussner, I., and Dröge-Laser, W. 2012. Transcriptional activation and production of tryptophan-derived secondary metabolites in Arabidopsis roots contributes to the defense against the fungal vascular pathogen Verticillium longisporum. Mol. Plant. 5:1389-402.

Karapapa, V. K., Bainbridge, B. W., and Heale, J. B. 1997. Morphological and molecular characterization of Verticillium longisporum comb. nov., pathogenic to oilseed rape. Mycol. Res. 101:1281-1293.

Kehr, J., Buhtz, A., and Giavalisco, P. 2005. Analysis of xylem sap proteins from Brassica napus. BMC Plant Biol. 5:11.

Kilberg, M. S., Shan, J., and Su, N. 2009. ATF4-dependent transcription mediates signaling of amino acid limitation. Trends Endocrin. Met. 20:436-443.

King, B. C., Waxman, K. D., Nenni, N. V., Walker, L. P., Bergstrom, G. C., and Gibson, D. M. 2011. Arsenal of plant cell wall degrading enzymes reflects host preference among plant pathogenic fungi. Biotechnol. Biofuels 4:4.

Kleinschmidt, M., Grundmann, O., Bluthgen, N., Mösch, H. U., and Braus, G. H. 2005. Transcriptional profiling of Saccharomyces cerevisiae cells under adhesion-inducing conditions. Mol. Genet. Genomics 273:382-393.

Klosterman, S. J., Subbarao, K. V., Kang, S., Veronese, P., Gold, S. E., Thomma, B. P., Chen, Z., Henrissat, B., Lee, Y. H., Park, J., GarciaPedrajas, M. D., Barbara, D. J., Anchieta, A., de Jonge, R., Santhanam, P., Maruthachalam, K., Atallah, Z., Amyotte, S. G., Paz, Z., Inderbitzin, 
P., Hayes, R. J., Heiman, D. I., Young, S., Zeng, Q., Engels, R., Galagan, J., Cuomo, C. A., Dobinson, K. F., and Ma, L. J. 2011. Comparative genomics yields insights into niche adaptation of plant vascular wilt pathogens. PLoS Pathog 7:e1002137. Published online.

Kolar, M., Punt, P. J., van den Hondel, C. A., and Schwab, H. 1988. Transformation of Penicillium chrysogenum using dominant selection markers and expression of an Escherichia coli lacZ fusion gene. Gene 62:127-134.

Krappmann, S., Bignell, E. M., Reichard, U., Rogers, T., Haynes, K., and Braus, G. H. 2004. The Aspergillus fumigatus transcriptional activator CpcA contributes significantly to the virulence of this fungal pathogen. Mol. Microbiol. 52:785-799.

Lazo, G. R., Stein, P. A., and Ludwig, R. A. 1991. A DNA transformationcompetent Arabidopsis genomic library in Agrobacterium. Biotechnology 9:963-967.

Livak, K. J., and Schmittgen, T. D. 2001. Analysis of relative gene expression data using real-time quantitative PCR and the $2-\Delta \Delta \mathrm{Ct}$ method. Methods 25:402-408.

Lopez-Millan, A. F., Morales, F., Abadia, A., and Abadia, J. 2000. Effects of iron deficiency on the composition of the leaf apoplastic fluid and xylem sap in sugar beet. Implications for iron and carbon transport. Plant Physiol 124:873-884.

Mösch, H. U., Scheier, B., Lahti, R., Mantsala, P., and Braus, G. H. 1991. Transcriptional activation of yeast nucleotide biosynthetic gene ADE4 by GCN4. J. Biol. Chem. 266:20453-20456.

Mullins, E. D., Chen, X., Romaine, P., Raina, R., Geiser, D. M., and Kang, S. 2001. Agrobacterium-mediated transformation of Fusarium oxysporum: An efficient tool for insertional mutagenesis and gene transfer. Phytopathology 91:173-180.

Nakayashiki, H. 2005. RNA silencing in fungi: Mechanisms and applications. FEBS Lett 579:5950-5957.

Nakayashiki, H., Hanada, S., Nguyen, B.Q., Kadotani, N., Tosa, Y., and Mayama, S. 2005. RNA silencing as a tool for exploring gene function in ascomycete fungi. Fungal Genet. Biol. 42:275-283.

Natarajan, K., Meyer, M. R., Jackson, B. M., Slade, D., Roberts, C. Hinnebusch, A. G., and Marton, M. J. 2001. Transcriptional profiling shows that Gcn $4 \mathrm{p}$ is a master regulator of gene expression during amino acid starvation in yeast. Mol. Cell Biol. 21:4347-4368.

Neumann, M. J., and Dobinson, K. F. 2003. Sequence tag analysis of gene expression during pathogenic growth and microsclerotia development in the vascular wilt pathogen Verticillium dahliae. Fungal Genet. Biol. 38:54-62.

Oliphant, A. R., Brandl, C. J., and Struhl, K. 1989. Defining the sequence specificity of DNA-binding proteins by selecting binding sites from random-sequence oligonucleotides: Analysis of yeast GCN4 protein Mol. Cell Biol. 9:2944-2949.

Paluh, J. L., Orbach, M. J., Legerton, T. L., and Yanofsky, C. 1988. The cross-pathway control gene of Neurospora crassa, cpc-1, encodes a protein similar to GCN4 of yeast and the DNA-binding domain of the oncogene v-jun-encoded protein. Proc. Natl. Acad. Sci. U.S.A. 85:37283732 .

Piotrowska, M., Kruszewska, A., and Paszewski, A. 1980. Effect of regulatory mutations of sulphur metabolism on the levels of cysteine- and homocysteine-synthesizing enzymes in Neurospora crassa. Acta Biochim. Pol. 27:395-403.

Ratzinger, A., Riediger, N., von Tiedemann, A., and Karlovsky, P. 2009. Salicylic acid and salicylic acid glucoside in xylem sap of Brassica napus infected with Verticillium longisporum. J. Plant Res. 122:571-579.

Saitou, N., and Nei, M. 1987. The neighbor-joining method: A new method for reconstructing phylogenetic trees. Mol. Biol. Evol. 4:406-425.

Sakuta, C., Oda, A., Yamakawa, S., and Satoh, S. 1998. Root-specific expression of genes for novel glycine-rich proteins cloned by use of an antiserum against xylem sap proteins of cucumber. Plant Cell Physiol. 39:1330-1336.

Sasse, C., Bignell, E. M., Hasenberg, M., Haynes, K., Gunzer, M., Braus, G. H., and Krappmann, S. 2008. Basal expression of the Aspergillus fumigatus transcriptional activator $\mathrm{CpcA}$ is sufficient to support pulmonary aspergillosis. Fungal Genet. Biol. 45:693-704.

Schnathorst, W. C. 1981. Life cycle and epidemiology of Verticillium. Pages 81-111 in: Fungal wilt diseases of plants. M. E. Mace, A. A. Bell, and C. H. Beckmann, eds. Academic Press, New York.

Schönig, B., Vogel, S., and Tudzynski, B. 2009. Cpc1 mediates cross-path- way control independently of Mbf1 in Fusarium fujikuroi. Fungal Genet. Biol. 46:898-908.

Schürch, A., Miozarri, J., and Hütter, R. 1974. Regulation of tryptophan biosynthesis in Saccharomyces cerevisiae: Mode of action of 5-methyltryptophan and 5-methyl-tryptophan-sensitive mutants J. Bacteriol 117:1131-1140.

Shan, J., Ord, D., Ord, T., and Kilberg, M. S. 2009. Elevated ATF4 expression, in the absence of other signals, is sufficient for transcriptional induction via CCAAT enhancer-binding protein-activating transcription factor response elements. J. Biol. Chem. 284:21241-21248.

Shen, W. C., and Ebbole, D. J. 1997. Cross-pathway and pathway-specific control of amino acid biosynthesis in Magnaporthe grisea. Fungal Genet. Biol. 21:40-49.

Singh, S., Braus-Stromeyer, S. A., Timpner, C., Tran, V. T., Lohaus, G., Reusche, M., Knufer, J., Teichmann, T., von Tiedemann, A., and Braus, G. H. 2010. Silencing of Vlaro2 for chorismate synthase revealed that the phytopathogen Verticillium longisporum induces the cross-pathway control in the xylem. Appl. Microbiol. Biotechnol. 85:1961-1976.

Singh, S., Braus-Stromeyer, S. A., Timpner, C., Valerius, O., von Tiedemann, A., Karlovsky, P., Druebert, C., Polle, A., and Braus, G. H. 2012. The plant host Brassica napus induces in the pathogen Verticillium longisporum the expression of functional catalase peroxidase which is required for the late phase of disease. Mol. Plant-Microbe Interact. 25:569-581.

Southern, E. M. 1975. Detection of specific sequences among DNA fragments separated by gel electrophoresis. J. Mol. Biol. 98:503-517.

Struhl, K., Brandl, C. J., Chen, W., Harbury, P. A., Hope, I. A., and Mahadevan, S. 1988. Transcriptional activation by yeast GCN4, a functional homolog to the jun oncoprotein. Cold Spring Harb Symp Quant Biol 53 Pt 2:701-709.

Tamura, K., Peterson, D., Peterson, N., Stecher, G., Nei, M., and Kumar, S. 2011. MEGA5: Molecular evolutionary genetics analysis using maximum likelihood, evolutionary distance, and maximum parsimony methods. Mol. Biol. Evol. 28:2731-2739.

Tian, C., Kasuga, T., Sachs, M. S., and Glass, N. L. 2007. Transcriptional profiling of cross pathway control in Neurospora crassa and comparative analysis of the Gen4 and CPC1 regulons. Eukaryot. Cell 6:10181029

Tilsner, J., Kassner, N., Struck, C., and Lohaus, G. 2005. Amino acid contents and transport in oilseed rape (Brassica napus L.) under different nitrogen conditions. Planta 221:328-338.

Tran, V. T., Braus-Stromeyer, S. A., Timpner, C., and Braus, G. H. 2013. Molecular diagnosis to discriminate pathogen and apathogen species of the hybrid Verticillium longisporum on the oilseed crop Brassica napus. Appl. Microbiol. Biotechnol. 97:4467-4483.

Tripathi, G., Wiltshire, C., Macaskill, S., Tournu, H., Budge, S., and Brown, A. J. 2002. Gcn 4 co-ordinates morphogenetic and metabolic responses to amino acid starvation in Candida albicans. EMBO (Eur. Mol. Biol. Organ.) J 21:5448-5456.

Valerius, O., Kleinschmidt, M., Rachfall, N., Schulze, F., Lopez Marin, S., Hoppert, M., Streckfuss-Bomeke, K., Fischer, C., and Braus, G. H. 2007. The Saccharomyces homolog of mammalian RACK1, Cpc2/Asc1p, is required for FLO11-dependent adhesive growth and dimorphism. Mol. Cell Proteomics 6:1968-1979.

Wanke, C., Eckert, S., Albrecht, G., van Hartingsveldt, W., Punt, P. J., van den Hondel, C. A., and Braus, G. H. 1997. The Aspergillus niger GCN4 homolog, cpcA, is transcriptionally regulated and encodes an unusual leucine zipper. Mol. Microbiol. 23:23-33.

Zeise, K., and Seidel, D. 1990. Zur entwicklung und schadwirkung der Verticillium welkekrankheit am winterraps. Raps 8:20-22.

Zeise, K., and von Tiedemann, A. 2001. Morphological and physiological differentiation among vegetative compatibility groups of Verticillium dahliae in relation to V. longisporum. J. Phytopathol. 149:469-475.

Zeise, K., and von Tiedemann, A. 2002a. Host Specialization among Vegetative Compatibility Groups of Verticillium dahliae in relation to Verticillium longisporum. J Phytopathology 150:112-119.

Zeise, K., and von Tiedemann, A. 2002b. Application of RAPD-PCR for virulence type analysis within Verticillium dahliae and $V$. longisporum J. Phytopathology 150:557-563.

Zhou, L., Hu, Q., Johannson, A., and Dixelius, C. 2006. Verticillium longisporum and Verticillium dahliae: Infection and disease in Brassica napus. Plant Pathol 55:137-144. 